\title{
Homo bacteriens and a network of surprises
}

The question 'are you a man or a mouse?' makes more sense in the microbiological context given that the average human being is composed of $10^{13}$ eukaryotic cells but contains $10^{14}$ prokaryotic cells [1], suggesting that Linnaeus should have named us Homo bacteriens. This raises a fundamental question - why does this enormous bacterial population, composed as it is of more than 1000 bacterial species, not induce a constant inflammatory response? After all, most commensal bacteria contain peptidoglycan and many contain one of the most potent pro-inflammatory components, lipopolysaccharide (LPS).

To account for the failure of our commensal microflora to induce inflammatory pathology we propose that these bacteria produce cytokine-like molecules which induce a network of cytokine interactions that inhibit local tissue inflammatory responses to commensal bacteria. This can occur by inhibiting the release or activity of cytokines that are proinflammatory, e.g., interleukin (IL)-1, IL-8, tumour necrosis factor (TNF), etc., or by inducing cytokines that have anti-inflammatory actions, e.g., IL-1 ra, IL10 , transforming growth factor (TGF)- $\beta_{1}$, or both. We further propose that local host factors interact with commensal bacteria controlling their growth, metabolism and virulence. These networks of prokaryotic and eukaryotic interactions control the inflammatory response to the resident microflora.

Is there any evidence to support these speculations? In recent reviews of the disparate papers on cytokineinducing components of bacteria we have established that bacteria produce a multitude of potent (and not so potent) cytokine-inducing proteins, carbohydrates and lipids [2-5]. We initially viewed these molecules as virulence factors and termed them modulins (in line with the other virulence factor classes - impedins, aggressins, etc.) as they modulate cell function via the induction of cytokine synthesis. Interestingly, some of the well-known bacterial toxins turned out to have potent cytokine-inducing activity, including haemolysins [6], Clostridium difficile toxin B [7] and Streptococcus pneumoniae pneumolysin [8], raising the possibility that the term 'toxin' may be a misnomer for these multifunctional proteins. The numbers and diversity of these cytokine-inducing molecules suggest that they play a more complex role than simply tickling the host's innate defence responses.

Transgenic 'knockout' mice in which the genes for
IL-2 or IL-10 had been inactivated developed severe colitis [9] or enterocolitis [10], respectively. With the IL-2 knockout, colitis was not due to the presence of specific pathogens and animals maintained under germ-free conditions did not develop any signs or symptoms of disease. Thus colitis was a response to the normal commensal microflora of the colon. We propose that, under normal conditions, the gut commensals produce signals that induce a particular network of cytokine interactions in the various cell populations in the gut and this dampens down local inflammation, possibly by regulating the balance of Th1:Th2 lymphocytes locally. However, in the absence of IL-2, this network cannot be produced and an inflammatory network of cytokine interactions ensues. Furthermore, in the IL-2 knockout, feedback from the gut epithelium to the commensal bacteria may be impaired, allowing the bacteria to produce large amounts of pro-inflammatory factors.

Viruses provide the third string to our hypothetical bow. Certain double-stranded DNA viruses produce a range of proteins that neutralise the activity of proinflammatory cytokines [11]. Many of these proteins are soluble forms of cytokine receptors that can bind and inactivate IL-1, TNF, interferons or chemokines. Similarly, the cowpox virus contains a gene $(\mathrm{crmA})$ coding for a protein that inhibits the activity of IL-1 $\beta$-converting enzyme [12] (a protease that cleaves the biologically active $17-\mathrm{kDa}$ protein from the $31-\mathrm{kDa}$ inactive precursor) and Epstein-Barr virus produces a protein, BCRF1, which is $84 \%$ identical to the antiinflammatory human cytokine - IL-10 [13].

The 60000 genes estimated to be in the human nucleus are but a fraction of the genes that exist in the 'bacterial genome'. Thus, based on the viral data, bacteria may produce a wide range of cytokine-like proteins with some having cytokine-modulating actions. Reports of such proteins have begun to appear recently. Perhaps the most interesting is a protein expressed by enteropathogenic strains of Escherichia coli that can inhibit the transcription of the genes for certain lymphokines, most notably IL-2, causing gut pathology similar to that seen in the IL-2 knockout mouse [14]. The fascinating oral bacterium Actinobacillus actinomycetemcomitans [15] produces: (i) an 8$\mathrm{kDa}$ anti-proliferative protein [16]; (ii) a $14-\mathrm{kDa}$ immunosuppressive protein that inhibits transcription of IL-2, IL-4, IL-5 and $\gamma$-interferon [17]; and (iii) a 2$\mathrm{kDa}$ peptide that directly induces transcription of IL-6, 
a unique mechanism, as all other IL-6 inducers work at second hand via the production of IL-1 or TNF [18]. Yersinia enterocolitica contains a gene, yop $\mathrm{B}$, encoding a $41-\mathrm{kDa}$ protein that specifically inhibits monocyte TNF production but not that of IL-1 or IL-6 [19]. Bacterial proteinases may also play a role in modulating cytokine networks by activating [20] or inactivating [21] particular cytokines.

Local host factors may conversely affect bacteria providing a two-way flow of information between the prokaryotic and eukaryotic populations constituting Homo bacteriens. A growing number of host proteins, including IL-1, IL-2, IL-6, TGF- $\beta_{1}$, insulin, and other less-defined proteins, stimulate growth of certain bacteria [4, 22]; numerous host defence peptides, variously termed cecropins, defensins, tachyplesins and magainins [23], may also play a role in host control of commensal bacterial growth and function.

The first bacterial cytokine network-modulating molecules are being discovered as we write. We need an appropriate terminology for these molecules. They cannot be called modulins as they are not virulence factors and the term bacteriokine springs to mind to describe these cytokine-like molecules. Given that viruses also produce these molecules, a more appropriate global term may be microkines. Whatever the name chosen, the search is now on for the molecules that produce the interacting networks which we envisage allow us to live in harmony with our commensal microflora.

B. HENDERSON and M. WILSON*, Maxillofacial Surgery Research Unit and * Department of Microbiology, Eastman Dental Institute University College London, 256 Gray's Inn Road London WC1X 8LD.

\section{References}

1. Tannock GW. Normal microflora. An introduction to microbes inhabiting the human body. London, Chapman and Hall. 1995.

2. Henderson B, Wilson M. Modulins: a new class of cytokineinducing, pro-inflammatory bacterial virulence factor. Inflamm Res 1995; 44: 187-197.

3. Henderson B, Wilson M. Cytokine induction by bacteria: beyond lipopolysaccharide. Cytokine 1996; 8: 269-282.

4. Henderson B, Poole S, Wilson M. Bacterial modulins: a novel class of virulence factors which cause host tissue pathology by inducing cytokine synthesis. Microbiol Rev 1996; 60: 316341
5. Henderson B, Poole S, Wilson M. Microbial/host interactions in health and disease: who controls the cytokine network? Immunopharmacology (in press)

6. Bhakdi S, Muhly M, Korom S, Schmidt G. Effects of Escherichia coli hemolysin on human monocytes: cytocidal action and stimulation of interleukin 1 release. $J$ Clin Invest 1990; 85: 1746-1753.

7. Flegel WA, Müller F, Däubener W, Fischer H-G, Hadding U, Northoff $H$. Cytokine response by human monocytes to Clostridium difficile toxin A and toxin B. Infect Immun 1991; 59: 3659-3666.

8. Houldsworth S, Andrew PW, Mitchell TJ. Pneumolysin stimulates production of tumor necrosis factor alpha and interleukin- $\beta$ by human mononuclear phagocytes. Infect Immun 1994; 62: 1501-1503.

9. Sadlack B, Merz H, Schorle H, Schimpl A, Feller AC, Horak I. Ulcerative colitis-like disease in mice with a disrupted interleukin-2 gene. Cell 1993; 75: 253-261.

10. Kühn R, Löhler J, Rennick D, Rajewsky K, Müller W. Interleukin-10-deficient mice develop chronic enterocolitis. Cell 1993; 75: 263-274.

11. Smith GL. Virus strategies for the evasion of the host response to infection. Trends Microbiol 1994; 2: 81-88.

12. Ray CA, Black RA, Kronheim SR et al. Viral inhibition of inflammation: cowpox virus encodes an inhibitor of the interleukin-1 $\beta$ converting enzyme. Cell 1992; 69: 597-604

13. Hsu D-H, de Waal Melefyt R, Fiorentino DF et al. Expression of interleukin-10 activity by Epstein-Barr virus protein BCRF1. Science 1990; 250: 830-832.

14. Klapproth J-M, Donnenberg MS, Abraham JM, Mobley HLT, James SP. Products of enteropathogenic Escherichia coli inhibit lymphocyte activation and lymphokine production. Infect Immun 1995; 63: 2248-2254.

15. Wilson M, Henderson B. Virulence factors of Actinobacillus actinomycetemcomitans relevant to the pathogenesis of inflammatory periodontal diseases. FEMS Microbiol Rev 1995; 17: 365-379.

16. White PA, Wilson M, Nair SP, Kirby AC, Reddi K, Henderson B. Characterization of an antiproliferative surface-associated protein from Actinobacillus actinomycetemcomitans which can be neutralized by sera from a proportion of patients with localized juvenile periodontitis. Infect Immun 1995; 63: 26122618.

17. Kurita-Ochiai T, Ochiai K. Immunosuppressive factor from Actinobacillus actinomycetemcomitans down-regulates cytokine production. Infect Immun 1996; 64: 50-54.

18. Reddi K, Nair SP, White PA et al. Surface-associated material from the bacterium Actinobacillus actinomycetemcomitans contains a peptide which, in contrast to lipopolysaccharide, directly stimulates fibroblast interleukin-6 gene transcription. Eur J Biochem 1996; 236: 871-876.

19. Beuscher HU, Rödel F, Forsberg $\AA$, Röllinghoff M. Bacterial evasion of host immune defense: Yersinia enterocolitica encodes a suppressor for tumor necrosis factor alpha expression. Infect Immun 1995; 63: 1270-1277.

20. Kapur V, Majesky MW, Li L-L, Black RA, Musser JM Cleavage of interleukin $1 \beta$ (IL-1 $\beta$ ) precursor to produce active IL- $1 \beta$ by a conserved extracellular cysteine protease from Streptococcus pyogenes. Proc Natl Acad Sci USA 1993; 90: 7676-7680.

21. Mintz CS, Miller RD, Gutgsell NS, Malek T. Legionella pneumophila protease inactivates interleukin-2 and cleaves CD4 on human T cells. Infect Immun 1993; 61: 3416-3421.

22. Kaprelyants AS, Kell DB. Do bacteria need to communicate with each other for growth? Trends Microbiol 1996; 4: 237 242.

23. Kelley KJ. Using host defenses to fight infectious diseases. Nature Biotechnology 1996; 14: 587-590. 